\title{
Optimization of process variables by response surface methodology for malachite green dye removal using lime peel activated carbon
}

\author{
Mohd Azmier Ahmad $^{1}$ - Nur Syahidah Afandi ${ }^{1}$ - Olugbenga Solomon Bello ${ }^{1,2}$
}

Received: 19 July 2014/ Accepted: 31 March 2015/Published online: 17 April 2015

(c) The Author(s) 2015. This article is published with open access at Springerlink.com

\begin{abstract}
This study investigates the adsorptive removal of malachite green (MG) dye from aqueous solutions using chemically modified lime-peel-based activated carbon (LPAC). The adsorbent prepared was characterized using FTIR, SEM, Proximate analysis and BET techniques, respectively. Central composite design (CCD) in response surface methodology (RSM) was used to optimize the adsorption process. The effects of three variables: activation temperature, activation time and chemical impregnation ratio (IR) using $\mathrm{KOH}$ and their effects on percentage of dye removal and LPAC yield were investigated. Based on CCD design, quadratic models and two factor interactions (2FI) were developed correlating the adsorption variables to the two responses. Analysis of variance (ANOVA) was used to judge the adequacy of the model. The optimum conditions of MG dye removal using LPAC are: activation temperature $\left(796{ }^{\circ} \mathrm{C}\right)$, activation time $(1.0 \mathrm{~h})$ and impregnation ratio (2.6), respectively. The percentage of MG dye removal obtained was $94.68 \%$ resulting in $17.88 \%$ LPAC yield. The percentage of error between predicted and experimental results for the removal of MG dye is $0.4 \%$. Model prediction was in good agreement with experimental results and LPAC was found to be effective in removing $\mathrm{MG}$ dye from aqueous solution.
\end{abstract}

Olugbenga Solomon Bello

osbello06@gmail.com

1 School of Chemical Engineering, Engineering Campus, Universiti Sains Malaysia, 14300 Nibong Tebal, Penang, Malaysia

2 Department of Pure and Applied Chemistry, Ladoke Akintola University of Technology, Ogbomoso P.M.B 4000, Oyo State, Nigeria
Keywords Lime peel $\cdot$ Activated carbon $\cdot$ Malachite green dye $\cdot$ Central composite design $\cdot$ Responses

\section{Introduction}

Leather, textile, paper and pulp industries discharge large quantities of highly coloured effluent containing dyes into nearby rivers or land without any treatment because conventional treatment methods are very expensive. Small amount of dye present in water $(<1 \mathrm{mg} / \mathrm{L})$, is highly visible and consequently undesirable (Sun and Yung 2003). Based on the chromophore group, 20-30 different groups of dyes are pollutants; therefore, removal of color from effluents is one of the major environmental problems. Different investigations on the effectiveness of low-cost adsorbents for effluent treatment of various applications have been carried out, e.g., perlite (Dogan et al. 2000), wheat straw (Robinson et al. 2002), straw carbon (Verma and Mishra 2006), periwinkle shell (Bello et al. 2008), banana stalk (Bello et al. 2012a, b, c), groundnut hull (Din et al. 2009; Bello et al. 2012b), oil palm ash (Hasan 2008; Foo and Hameed 2009a), oil palm fruit fibre (Bello 2013), cocoa pod husks (Bello and Ahmad 2011a), mango peels (Bello and Ahmad 2011b), rice husk (Foo and Hameed 2009b; Yahaya et al. 2010a, b, 2011a, b); Bello and Ahmad 2011c, d), palm kernel shell (Zawani et al. 2009), coconut shell (Bello and Ahmad 2012b), Imperata cylindrica leaf (Bello and Semire 2012), rubber seed coat (Bello and Ahmad 2012a) and fly ash (Bello et al. 2013). The dye under investigation, Malachite green is used to colour silk, leather and paper. It is water-soluble, found as contaminant in industrial effluents. Clinical and experimental observations reported so far reveal that malachite green is a multi-organ toxin. Malachite green is highly cytotoxic to mammalian cells and 
carcinogenic to liver, thyroid and other organs in animals (Sundarrajan et al. 2000).

Musk lime (Citrus microcarpa) from family Rutaceae is commonly found in Malaysia, Thailand, Indonesia and Philippines (Abdullah et al. 2012). The health benefits of lime include skin care, eye care, weight loss, good digestion, relief from constipation, and treatment of scurvy. Besides that, the juice is also commonly used as a flavoring ingredient in desserts or as an additive in various food preparations such as fish steak, jams, candies, and marmalade. The pulp of the fruit is used as a major ingredient in purees, syrups, concentrates, and beverages. The peel of musk lime is rough and usually discarded. Thus, utilization of musk lime peel for AC production is a way of placing value on this waste thereby saving disposal cost. As a result of the hazardous health effects of MG dye, the present study is aimed at removing this dye from wastewater using musk lime peel as adsorbent by employing a central composite design (CCD) in response surface methodology (RSM) Design Expert software version 7.1.5.1 (STATEASE Inc., Minneapolis, USA). RSM was selected to elucidate the simultaneous effects of parameters on the adsorption process. The multiple regression analysis technique in the RSM was utilized to develop the equations and empirical models correlating the dye removal efficiency and activated carbon yield to three adsorption variables. The analysis of variance (ANOVA) was employed to judge the adequacy of the model. The optimized conditions developed from the model were validated experimentally and the feasibility of LPAC for MG dye removal was obtained.

\section{Materials and methods}

\section{Adsorbate used}

MG dye was supplied by Sigma-Aldrich (M) Sdn Bhd, Malaysia and used as received. MG has a chemical formula of $\mathrm{C}_{52} \mathrm{H}_{54} \mathrm{~N}_{4} \mathrm{O}_{12}$, molecular weight of $927.00 \mathrm{~g} / \mathrm{mol}$ and $\lambda_{\max }=618 \mathrm{~nm}$. Stock solutions were prepared by dissolving accurately weighed samples of dye in deionized water.

\section{Activated carbon preparation}

Musk lime peel (LP) used as precursors for AC preparation was obtained from Lembaran, Café, Universiti Sains Malaysia. Malaysia. It was cleansed and rinsed thoroughly with distilled water. It was then dried to constant weight and stored in an air tight container for further use.

$100 \mathrm{~g}$ of dried musk lime peel was ground into small pieces using an electric crusher and sieved using endecotte sieves to the desired particle size of 1-2 $\mathrm{mm}$ and loaded in a stainless steel vertical tubular reactor $(l 140 \mathrm{~mm}, d$
$73 \mathrm{~mm}$, i.d. $67 \mathrm{~mm}$ ) placed in a tube furnace ( $480 \mathrm{~mm}, d$ $89 \mathrm{~mm}$, i.d. $83 \mathrm{~mm})$. The flow rate of nitrogen gas and the heating rate were held at $150 \mathrm{~cm}^{3} / \mathrm{min}$ and $10{ }^{\circ} \mathrm{C} / \mathrm{min}$, respectively. The temperature was ramped from room temperature to $850{ }^{\circ} \mathrm{C}$ and held for $1 \mathrm{~h}$. Then, the reactor was cooled down to room temperature. The char produced was stored in an airtight container for further treatment. The char produced was then impregnated using $\mathrm{KOH}$. The impregnation ratio (IR) was calculated using;

$\mathrm{IR}=\frac{w_{\mathrm{KOH}}}{w_{\mathrm{char}}}$

where $w_{\mathrm{KOH}}$ is the dry weight $(\mathrm{g})$ of potassium hydroxide pellet and $w_{\text {char }}$ is the dry weight $(\mathrm{g})$ of char. The char and $\mathrm{KOH}$ powder (depending on the IR) were mixed together with deionized water in a $250 \mathrm{ml}$ beaker. The mixture was allowed to dry in the oven at $105{ }^{\circ} \mathrm{C}$ for $12 \mathrm{~h}$. The $\mathrm{KOH}$ impregnated char was placed inside the vertical tubular reactor for activation process. The system was purged under nitrogen flow of $150 \mathrm{~cm}^{3} / \mathrm{min}$. The temperature was ramped from ambient temperature to the activation temperature of $850{ }^{\circ} \mathrm{C}$ at heating rate of $10{ }^{\circ} \mathrm{C} / \mathrm{min}$. Once the desired activation temperature was reached $\left(850{ }^{\circ} \mathrm{C}\right)$, the gas flow was switched to carbon dioxide at flow rate of $150 \mathrm{~cm}^{3} / \mathrm{min}$ to complete the activation process. Then, the reactor was cooled to room temperature under nitrogen flow. The sample was washed with $0.1 \mathrm{M} \mathrm{HCl}$. It was further washed with deionized water several times until the $\mathrm{pH}$ of the washing solution reached 6.5-7. The $\mathrm{pH}$ was measured using $\mathrm{pH}$ meter (Model Delta 320, Mettler Toledo, China). Filter paper and filter funnel were used in the washing process. The washed sample was kept in an oven at $105{ }^{\circ} \mathrm{C}$ for $12 \mathrm{~h}$. The dried sample, which was the activated carbon (LPAC), was stored in airtight containers for optimization, adsorption and characterization studies. The LPAC yield was calculated using the equation:

Yield $(\%)=\frac{w_{\mathrm{c}}}{w_{0}} \times 100$

where $w_{\mathrm{c}}$ and $w_{0}$ are the dry weight of LPAC (g) and the dry weight of precursor $(\mathrm{g})$, respectively.

\section{Adsorption studies}

For batch adsorption studies, $0.2 \mathrm{~g}$ of LPAC was mixed with $100 \mathrm{ml}$ aqueous dye solution of $100 \mathrm{mg} / \mathrm{L}$ initial concentration in 20 sets of $250-\mathrm{ml}$ Erlenmeyer flasks. The mixture was agitated at $120 \mathrm{rpm}$ at $30{ }^{\circ} \mathrm{C}$ until equilibrium was reached. The concentration of $\mathrm{MG}$ dye solution was determined using a UV-visible spectrophotometer (UV1800 Shimadzu, Japan) at a maximum wavelength of $618 \mathrm{~nm}$. The percentage of dye removal at equilibrium was calculated using Eq. (3): 
$\operatorname{Removal}(\%)=\frac{C_{0}-C_{\mathrm{e}}}{C_{0}} \times 100$

where $C_{\mathrm{o}}$ and $C_{\mathrm{e}}$ are the liquid-phase dye concentrations at initial and equilibrium states $(\mathrm{mg} / \mathrm{L})$, respectively.

\section{Characterization of LPAC}

Fourier transform infrared (FTIR) spectroscopic analysis was performed (FTIR-2000, Perkin Elmer). The FTIR spectra give information about the characteristic functional groups on the surface of the sample. The spectra were measured from 4000 to $400 \mathrm{~cm}^{-1}$. The surface area, total pore volume, and average pore diameter of the samples were determined from the adsorption isotherms of nitrogen at $77 \mathrm{~K}$ using Autosorb I, supplied by Quantachrome Corporation, USA. Mesopore volume was calculated by subtracting total volume, obtained at a relative pressure of 0.99 from the micropore volume obtained from t-plot equation. The surface morphology of the sample was examined using scanning electron microscope (Model VPFESEM Supra 35VP). Proximate analysis (Wasewar et al. 2009) was carried out using thermo gravimetric analyzer (TGA) (Model Perkin Elmer TGA7, USA).

\section{Experimental design using CCD}

A standard response surface methodology (RSM) design known as central composite design (CCD) was used to study the parameter for AC preparation. In this work, three independent variables were studied for the AC preparation; they are: $x_{1}$, activation temperature $\left({ }^{\circ} \mathrm{C}\right), x_{2}$, activation time (h), and $x_{3}$, impregnation ratio (IR). The ranges and the levels of the variables investigated. Based on the ranges and the levels given, a complete design matrix of the experiments was employed as shown in Table 1 . There are 8 factorial points, 6 axial points and 6 replicates at the center points, indicated by a total of 20 experiments for each precursor, as calculated from Eq. 4:

$N=2^{n}+2 n+n=2^{3}+2 \times 3+6=20$

where $N$ is the total number of experiments required and $n$ is the number of variables. The center points were used to verify the reproducibility of the data and the experimental error. The variables were coded to the $(-1,1)$ interval where low and high level were coded as -1 and +1 , respectively. The axial points are located at $( \pm \alpha, 0,0)(0$, $\pm \alpha, 0)$ and $(0,0, \pm \alpha)$ where $\alpha$ is the distance of the axial point from center and makes the design rotatable. In this study, $\alpha$ value was fixed at 1.682 (rotatable). The two responses are MG removal $\left(Y_{1}\right)$ and LPAC yield $\left(Y_{2}\right)$. Each response was used to develop an empirical model which correlated the response to the variables using a second-
Table 1 Pore characteristics and surface area of samples

\begin{tabular}{lclll}
\hline Sample & $\begin{array}{l}\text { BET surface } \\
\text { area }\left(\mathrm{m}^{2} / \mathrm{g}\right)\end{array}$ & $\begin{array}{l}\text { Mesopore } \\
\text { surface area } \\
\left(\mathrm{m}^{2} / \mathrm{g}\right)\end{array}$ & $\begin{array}{l}\text { Total pore } \\
\text { volume } \\
\left(\mathrm{cm}^{3} / \mathrm{g}\right)\end{array}$ & $\begin{array}{l}\text { Average pore } \\
\text { diameter }(\mathrm{nm})\end{array}$ \\
\hline LP raw & 2.24 & - & - & - \\
LP char & 88.17 & 61.60 & 0.134 & 5.43 \\
LPAC & 903.65 & 585.32 & 0.450 & 5.57 \\
\hline
\end{tabular}

degree polynomial equation as follow (Zainudin et al. 2005):

$Y=b_{0}+\sum_{i=1}^{n} b_{i} x_{i}+\left(\sum_{i=1}^{n} b_{i i} x_{i}\right)^{2}+\sum_{i=1}^{n-1} \sum_{j=i+1}^{n} b_{i j} x_{i} x_{j}$

where $Y$ is the predicted response, $b_{0}$ the constant coefficient, $b_{i}$ the linear coefficients, $b_{i j}$ the interaction coefficients, $b_{i i}$ the quadratic coefficients and $x_{i}, x_{j}$ are the coded values of the AC preparation variables. The coefficient with one factor represents the effect of particular factor, while the coefficient with two factors and those with second-order terms represent the interaction between two factors and quadratic effects. In order to strike a compromise between the responses, the function of desirability was applied by using Design Expert software version 7.1.5.1 (STAT-EASE Inc., Minneapolis, USA). The "prob $>F$ " value of less than 0.05 indicates that the model is significant (Ahmad and Hameed 2010). It is desirable to indicate the influence of particular model terms that have significant effects on the response. Experimental conditions with the highest desirability were selected to be verified.

\section{Result and discussion}

\section{Sample characterization}

Pore characteristics, surface area, surface morphology, surface chemistry and proximate analysis were studied to characterize the LPAC sample.

\section{Pore characteristics and surface area}

The pore characteristics of the LPAC are given in Table 1 and consist of BET surface area, mesopores surface area, total pore volume and average pore diameter. As can be seen from the Table, surface area of the sample was found to increase significantly throughout the preparation of $\mathrm{AC}$. LPAC has a relatively high BET surface area of $903.65 \mathrm{~m}^{2} /$ g. The high BET surface area and total pore volumes were due to the activation process used, which involved both chemical and physical activating agents of $\mathrm{KOH}$ and $\mathrm{CO}_{2}$. Diffusion of $\mathrm{KOH}$ and $\mathrm{CO}_{2}$ molecules into the pores have 
increased the $\mathrm{KOH}$-carbon and $\mathrm{CO}_{2}$-carbon reactions which then developed more pores in the LPAC. This result agrees with the study carried out on preparation of highly porous carbon from fir wood by $\mathrm{KOH}$ etching and $\mathrm{CO}_{2}$ gasification for adsorption of dyes and phenols from water (Wu and Tseng 2006; Li et al. 2008).

The average pore diameter for LPAC was $5.57 \mathrm{~nm}$, which is categorized in mesopore region according to the IUPAC classification (IUPAC 1972). The significant increase in surface area was attributed to intercalation of potassium metal from intermediate reaction of $\mathrm{KOH}$ with carbon (Sudaryanto et al. 2006).

\section{Surface morphology (SEM)}

SEM was used to characterize the surface morphology of the sample as shown in Fig. 1a and b, respectively. No pore was detected in LP whereas large pores were clearly found on the surface of the LPAC compared to LP. The welldeveloped pores resulted in larger surface area and more porous structure of the LPAC which would further enhance the adsorption process (Bello et al. 2012a, b, c). LPAC micrographs illustrated heterogeneous pore distribution. High activation temperature and IR applied were believed to be responsible for pore development in LPAC. The
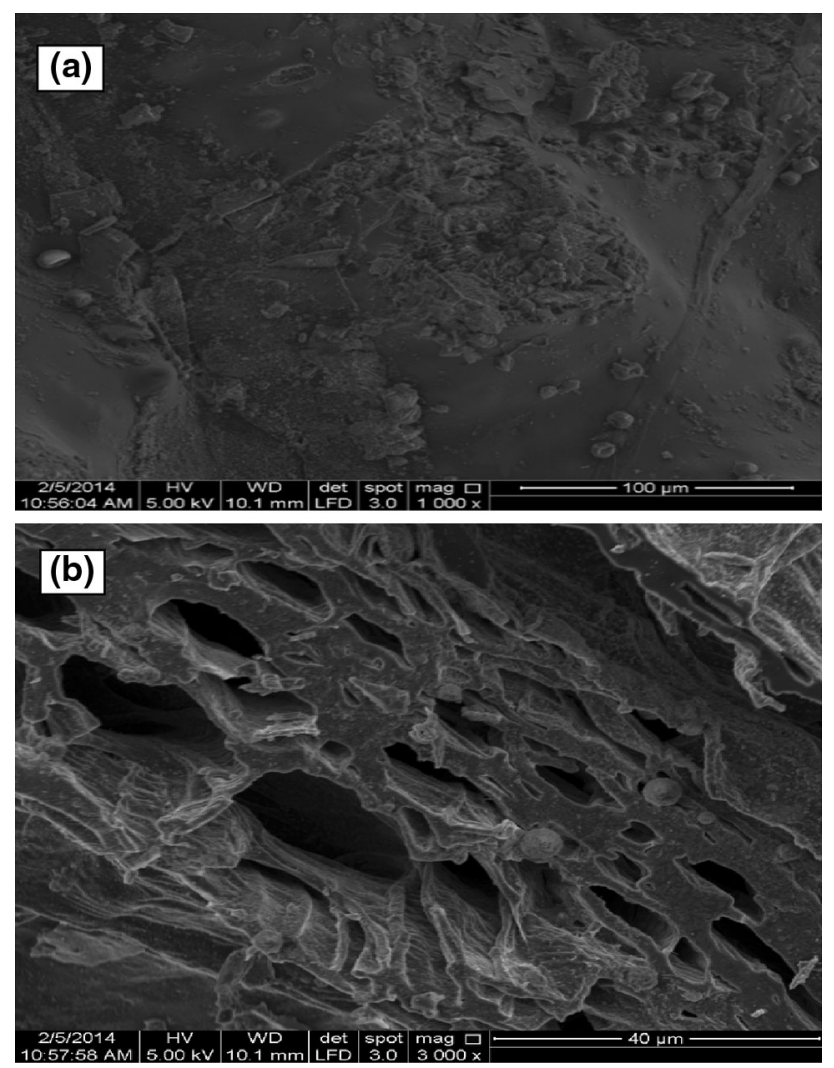

Fig. 1 SEM micrographs of a LP (×3000) and b LPAC $(\times 3000)$
$\mathrm{C}-\mathrm{KOH}$ (activated carbon impregnated with $\mathrm{KOH}$ ) reaction rate was increased during activation process, which resulting in increased carbon "burn-off" and porosity in samples. The $\mathrm{C}-\mathrm{KOH}$ reaction also increased the porosity of the existing pore as well as creating new pores (Auta and Hameed 2011). Besides, the physiochemical treatment was able to produce porous AC thus increasing the surface area that will enhance the higher adsorption capacity. $\mathrm{KOH}$ treatment facilitates the widening of tobacco residue-based AC pores (TRAC). Raw tobacco residue was found to have very little porosity whereas the surface of TRAC was full of cavities (Kilic et al. 2011).

\section{Surface chemistry}

FTIR spectral assignments for LP, LP char and LPAC is shown in Fig. 2. The spectra revealed various functional groups detected on the surface of LPAC. Four significant bands were detected; they are $\mathrm{OH}$ stretching vibrations at bandwidth around $3500-3800 \mathrm{~cm}^{-1}, \mathrm{C} \equiv \mathrm{C}$ stretching vibrations at $2340-2420 \mathrm{~cm}^{-1}, \mathrm{C}=\mathrm{C}$ stretching vibration in aromatic ring at $1500-1650 \mathrm{~cm}^{-1}$ and $=\mathrm{C}-\mathrm{H}$ stretching vibrations of alkane group around $2900-2920 \mathrm{~cm}^{-1}$. These bands indicate the possible involvements of these functional groups on the surface of LPAC in dye adsorption process (Sathishkumar et al. 2006). LP and LPAC surface chemistry were found to be different as some of the functional groups disappeared due to the activation process, which shows that these functional groups were thermally unstable. From Fig. 2, there is a decrease in the absorption band of aromatic group from LP to LPAC due to oxidative degradation of aromatic rings during chemical impregnation and heat treatment stages.

\section{Proximate and ultimate analysis}

Proximate analysis of LP samples are shown in Table 2. LP was found to be rich in moisture and volatile matter. It can be seen that the moisture and volatile matter content for both materials was sharply reduced from precursor to AC. During carbonization process, high temperature condition resulted in reduction in volatile matter and moisture content. Further reduction in volatile matter occurred during the activation step. Meanwhile, the fixed carbon increased drastically from raw material to AC for both samples. The same trend was observed in the carbon content in the ultimate analysis of LP. This was due to the heat supplied during carbonization process which initiated the thermal degradation process. The volatile substances inside could not maintain their stability at high temperature due to the breakage of bonds and linkages in the molecule (Bello et al. 2012a, b, c). 
Fig. 2 Surface chemistry of a LP b LP char and c LPAC
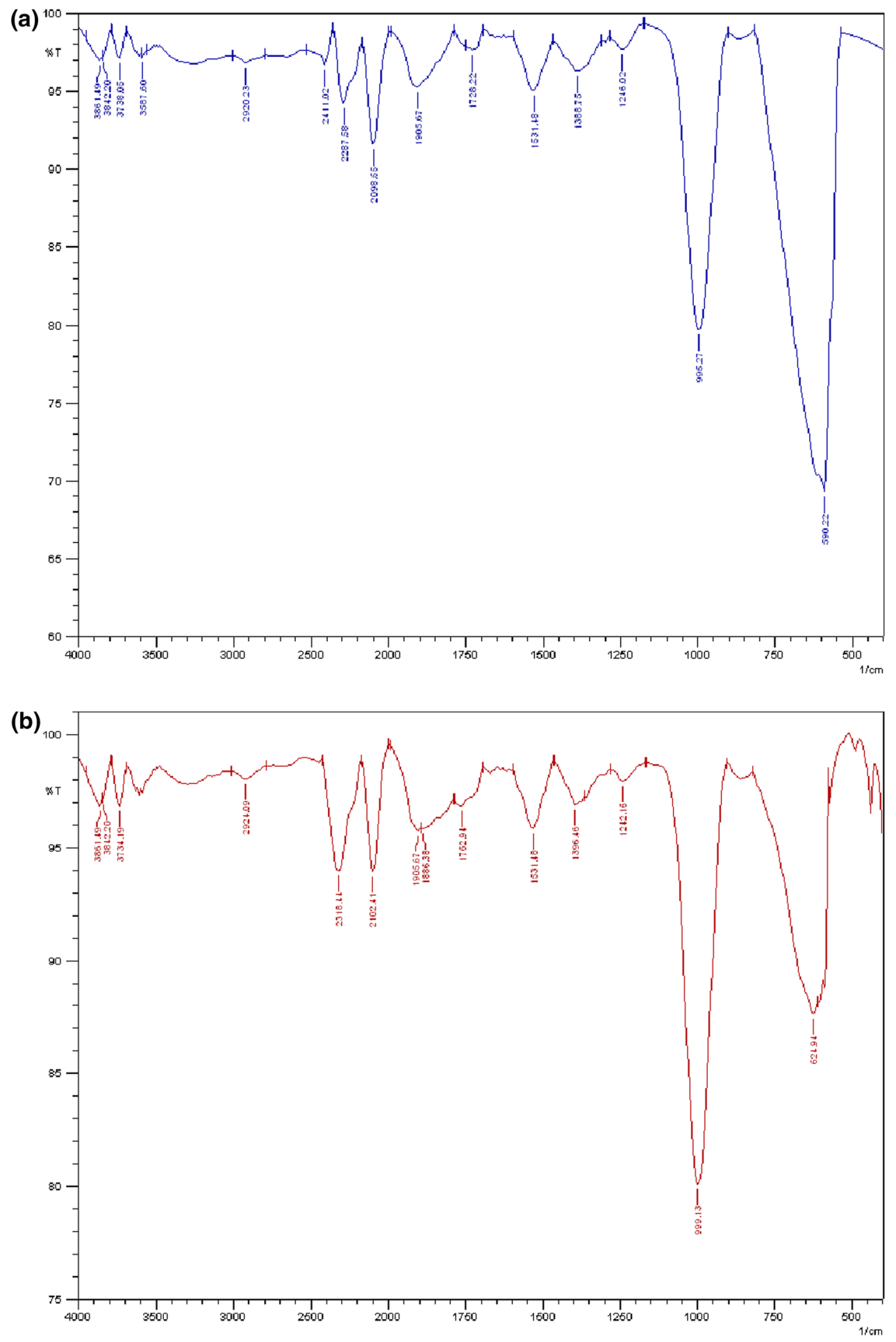

Model fitting and statistical analysis

Design Expert Software version 7.1.5.1 (STAT-EASE Inc., Minneapolis, US) was used to analyze the experimental data.

\section{Development of regression model equation of LPAC}

Experimental design for preparing ACs from lime peel (LP) was studied. Response surface methodology (RSM) was used to design the experimental work. Three variables 
Fig. 2 continued

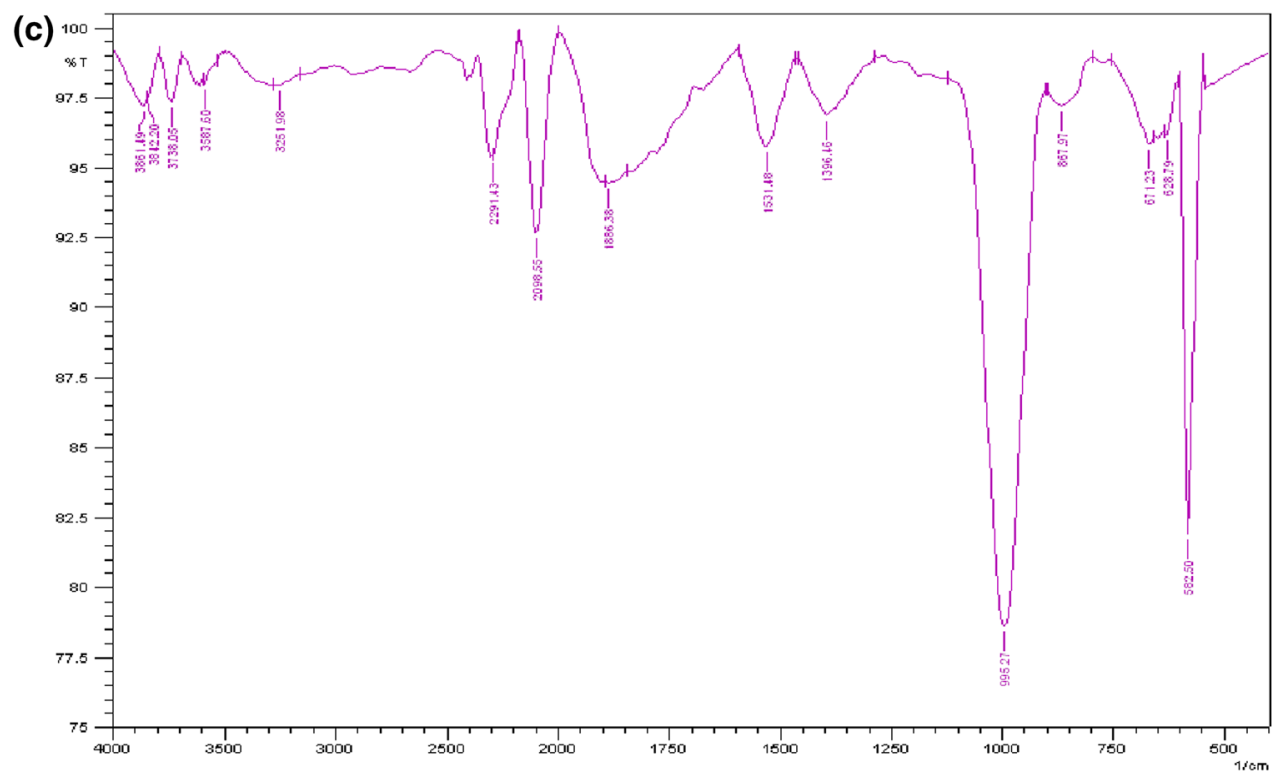

Table 2 Proximate and ultimate analyses of samples

\begin{tabular}{|c|c|c|c|c|c|c|c|c|}
\hline \multirow[t]{2}{*}{ Sample } & \multicolumn{4}{|c|}{ Proximate analysis (\%) } & \multicolumn{4}{|c|}{ Ultimate analysis (\%) } \\
\hline & Moisture & Volatile & Fixed carbon & Ash & $\mathrm{C}$ & $\mathrm{H}$ & $\mathrm{S}$ & $(\mathrm{N}+\mathrm{O})^{\mathrm{a}}$ \\
\hline LP & 7.25 & 66.30 & 22.91 & 3.54 & 20.74 & 8.87 & 0.19 & 70.20 \\
\hline LP char & 3.17 & 23.41 & 70.11 & 3.31 & 69.24 & 4.08 & 0.35 & 26.33 \\
\hline LPAC & 2.29 & 16.09 & 78.42 & 3.20 & 79.21 & 2.57 & 0.18 & 18.04 \\
\hline
\end{tabular}

${ }^{\text {a }}$ Estimated by difference

studied were; activation temperature $\left(x_{1}\right)$, activation time $\left(x_{2}\right)$ and $\mathrm{KOH} /$ char IR $\left(x_{3}\right)$ with two responses; MG removal, $Y_{1}(\%)$ and LPAC yield, $Y_{2}(\%)$. These variables were chosen based on the literature and results obtained from the preliminary studies. Design Expert Software was used to analyze the experimental data. The models were selected based on the highest order polynomials where the additional terms were significant. From the data for dye removal in Table 3, quadratic model was generated by RSM as it was statistically significant for MG dye removal response $\left(Y_{1}\right)$. Meanwhile, for LPAC yield $\left(Y_{2}\right)$, two factor interaction (2FI) model was chosen. RSM generates empirical model in term of coded factors which reflects the interaction and significance of variables towards response. The coefficient with one factor stand for the effect of the particular factor only, whereas the coefficients with two factors and also with second-order term correspond to the interaction between two factors and quadratic effect, respectively. The final empirical formula models for the responses in terms of coded factors are represented by Eqs. 6 and 7 , respectively.
MG removal $\left(Y_{1}\right)$;

$$
\begin{aligned}
Y_{1}= & 94.13+4.53 x_{1}+0.57 x_{2}+5.92 x_{3}-0.52 x_{1}^{2} \\
& -1.20 x_{2}^{2}-0.32 x_{3}^{2}-3.51 x_{1} x_{2}-0.87 x_{1} x_{3} \\
& -4.07 x_{2} x_{3}
\end{aligned}
$$

LPAC yield $\left(Y_{2}\right)$;

$$
\begin{aligned}
Y_{2}= & 17.72-1.63 x_{1}-1.26 x_{2}-1.23 x_{3}-0.87 x_{1} x_{2} \\
& +0.067 x_{1} x_{3}-0.18 x_{2} x_{3}
\end{aligned}
$$

Correlation coefficient, $R^{2}$ value was important for validation of the model developed. The $R^{2}$ values for Eqs. 6 and 7 are 0.9839 and 0.8971 , respectively. This indicates 98.39 and $89.71 \%$ of the total variation in the MG dye and LPAC yield correlation between the experimental and predicted values, respectively. These high $R^{2}$ values indicate that the predicted responses were close to the experimental values and the models are suitable to correlate with the experiment data. Therefore, the $R^{2}$ shows good agreement between experimental data. These are shown in Figs. 3 and 4, respectively. Furthermore, low standard deviation values of 1.38 and 0.87 are obtained for the two 
Table 3 Matrix for LPAC preparation variables and responses

\begin{tabular}{|c|c|c|c|c|c|c|c|c|}
\hline \multirow[t]{2}{*}{ Run } & \multirow[t]{2}{*}{ Level } & & & \multicolumn{3}{|c|}{ LPAC preparation variables } & \multirow{2}{*}{$\begin{array}{l}\text { MG removal, } \\
Y 1(\%)\end{array}$} & \multirow{2}{*}{$\begin{array}{l}\text { LPAC yield, } \\
Y 2(\%)\end{array}$} \\
\hline & & & & $\begin{array}{l}\text { Activation } \\
\text { temperature, } x_{1}\left({ }^{\circ} \mathrm{C}\right)\end{array}$ & $\begin{array}{l}\text { Activation } \\
\text { time, } x_{2}(\mathrm{~h})\end{array}$ & $\mathrm{IR}, x_{3}$ & & \\
\hline 1 & -1 & -1 & -1 & 700 & 1.00 & 1.00 & 73.87 & 21.53 \\
\hline 2 & +1 & -1 & -1 & 850 & 1.00 & 1.00 & 84.29 & 18.65 \\
\hline 3 & -1 & +1 & -1 & 700 & 3.00 & 1.00 & 75.67 & 20.73 \\
\hline 4 & +1 & +1 & -1 & 850 & 3.00 & 1.00 & 85.43 & 15.60 \\
\hline 5 & -1 & -1 & +1 & 700 & 1.00 & 3.50 & 88.81 & 19.12 \\
\hline 6 & +1 & -1 & +1 & 850 & 1.00 & 3.50 & 95.85 & 17.74 \\
\hline 7 & -1 & +1 & +1 & 700 & 3.00 & 3.50 & 90.76 & 18.82 \\
\hline 8 & +1 & +1 & +1 & 850 & 3.00 & 3.50 & 94.29 & 12.73 \\
\hline 9 & -1.682 & 0 & 0 & 649 & 2.00 & 2.50 & 74.32 & 19.95 \\
\hline 10 & 1.682 & 0 & 0 & 901 & 2.00 & 2.50 & 92.86 & 15.89 \\
\hline 11 & 0 & -1.682 & 0 & 775 & 0.32 & 2.50 & 89.73 & 18.66 \\
\hline 12 & 0 & 1.682 & 0 & 775 & 3.68 & 2.50 & 92.35 & 13.90 \\
\hline 13 & 0 & 0 & -1.682 & 775 & 2.00 & 0.15 & 72.95 & 20.37 \\
\hline 14 & 0 & 0 & 1.682 & 775 & 2.00 & 4.35 & 91.05 & 15.21 \\
\hline 15 & 0 & 0 & 0 & 775 & 2.00 & 2.25 & 94.73 & 17.45 \\
\hline 16 & 0 & 0 & 0 & 775 & 2.00 & 2.25 & 93.59 & 17.81 \\
\hline 17 & 0 & 0 & 0 & 775 & 2.00 & 2.25 & 93.69 & 17.92 \\
\hline 18 & 0 & 0 & 0 & 775 & 2.00 & 2.25 & 94.67 & 17.05 \\
\hline 19 & 0 & 0 & 0 & 775 & 2.00 & 2.25 & 93.71 & 17.69 \\
\hline 20 & 0 & 0 & 0 & 775 & 2.00 & 2.25 & 94.63 & 17.53 \\
\hline
\end{tabular}

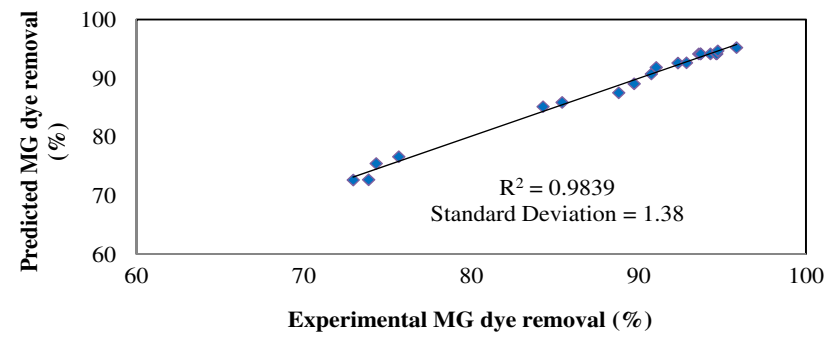

Fig. 3 Predicted versus experimental MG dye removal of LPAC

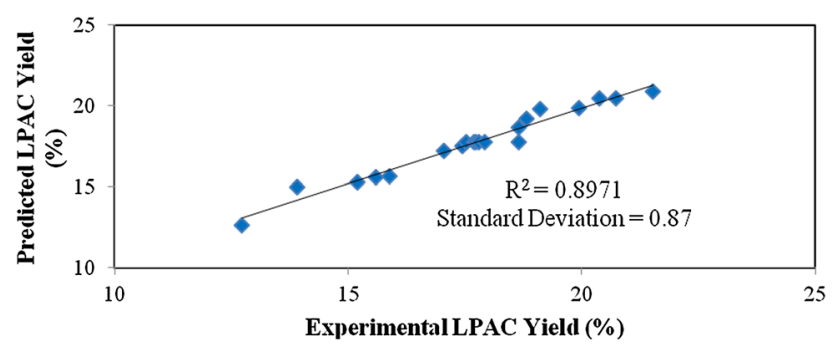

Fig. 4 Predicted versus experimental LPAC yield

models, respectively. The complete design matrix for preparing (LPAC) is given in Table 3. For the responses, the model coefficient was estimated using multiple regression analysis technique in RSM.
The significance and adequacy of the models were justified through analysis of variance (ANOVA). The mean squares were obtained by dividing the sum of the squares of each of the variable sources, the model and the error variance, by the respective degree of freedom. Low value of Prob $>F$ less than 0.05 indicates that result is not random and the term model has a significant effect to the response (Sahu et al. 2010). The ANOVA for the quadratic model of MG dye removal by LPAC is shown in Table 4 . From the Table, model $F$ value of 67.97 and value "Prob $>F$ " of 0.0001 , implies the model was significant. In this case, activation temperature $\left(x_{1}\right)$, IR $\left(x_{3}\right)$ as well as quadratic $\left(x_{1}^{2}, x_{2}^{2}, x_{3}^{2}\right)$ factors and the interaction term of pyrolysis temperature and IR $\left(x_{1} x_{3}\right)$ were significant models. Whereas activation time $\left(x_{2}\right)$ and the interaction terms of $x_{1} x_{2}$, and $x_{2} x_{3}$ were all insignificant to their responses.

The ANOVA for 2FI model for LPAC yield is shown in Table 5. From this Table, the model $F$ value of 18.89 and Prob. $>F$ of less than 0.0001 indicated that LPAC yield model was significant. The model term $x_{1}, x_{2}, x_{3}$ and $x_{1} x_{2}$ were significant models whereas $x_{1} x_{3}$ and $x_{2} x_{3}$ were insignificant to the responses. Therefore, it can be concluded that the above models (Eqs. 6, 7) were adequate to predict the MG dye removal and the LPAC yield within the range of variables studied. 
Table 4 ANOVA analysis for MG dye removal using LPAC

\begin{tabular}{lrlrrr}
\hline Source & $\begin{array}{l}\text { Sum of } \\
\text { squares }\end{array}$ & $\begin{array}{l}\text { Degree of } \\
\text { freedom (DF) }\end{array}$ & $\begin{array}{l}\text { Mean } \\
\text { square }\end{array}$ & $F$ value & Prob $>F$ \\
\hline Model & 1158.40 & 9 & 128.71 & 67.97 & $<0.0001$ \\
$x_{1}$ & 240.84 & 1 & 240.84 & 148.31 & $<0.0001$ \\
$x_{2}$ & 4.38 & 1 & 4.38 & 2.31 & 0.1592 \\
$x_{3}$ & 479.12 & 1 & 479.12 & 253.03 & $<0.0001$ \\
$x_{1}^{2}$ & 177.37 & 1 & 177.37 & 93.67 & $<0.0001$ \\
$x_{2}^{2}$ & 11.01 & 1 & 11.01 & 5.82 & 0.0366 \\
$x_{3}^{2}$ & 238.76 & 1 & 238.76 & 126.09 & $<0.0001$ \\
$x_{1} x_{2}$ & 2.17 & 1 & 2.17 & 1.15 & 0.3092 \\
$x_{1} x_{3}$ & 11.54 & 1 & 11.54 & 6.10 & 0.0332 \\
$x_{2} x_{3}$ & 0.81 & 1 & 0.81 & 0.43 & 0.5271 \\
\hline
\end{tabular}

Table 5 ANOVA analysis for LPAC yield

\begin{tabular}{lllllr}
\hline Source & $\begin{array}{l}\text { Sum of } \\
\text { squares }\end{array}$ & $\begin{array}{l}\text { Degree of } \\
\text { freedom (DF) }\end{array}$ & $\begin{array}{l}\text { Mean } \\
\text { square }\end{array}$ & $F$ value & Prob $>F$ \\
\hline Model & 84.99 & 6 & 14.16 & 18.89 & $<0.0001$ \\
$x_{1}$ & 36.44 & 1 & 36.44 & 48.60 & $<0.0001$ \\
$x_{2}$ & 21.58 & 1 & 21.58 & 28.77 & 0.0001 \\
$x_{3}$ & 20.61 & 1 & 20.61 & 27.49 & 0.0002 \\
$x_{1} x_{2}$ & 6.06 & 1 & 6.06 & 8.08 & 0.0139 \\
$x_{1} x_{3}$ & 0.036 & 1 & 0.036 & 0.049 & 0.8289 \\
$x_{2} x_{3}$ & 0.27 & 1 & 0.27 & 0.36 & 0.5613 \\
\hline
\end{tabular}

\section{MG dye removal using LPAC}

The $F$ value tabulated in Table 4 verified that $x_{3}$ imposed the most significant effect, followed by $x_{1}$ and $x_{2}$ on MG dye removal by LPAC. As seen in Table 4, interaction of activation temperature and IR, denoted by $x_{1} x_{3}$ were profound than the interaction of $x_{1} x_{2}$ and $x_{2} x_{3}$ as it showed highest $F$ value of 6.10 . Figure 5 illustrate the three-dimensional response surface which shows the effects of the two significant variables $\left(x_{1}\right.$ and $\left.x_{3}\right)$ where the $x_{2}$ was fixed at zero level $(t=2 \mathrm{~h})$. It was observed that the maximum MG dye removal was achieved at the activation temperature range between 730 and $850{ }^{\circ} \mathrm{C}$ and IR 1.5-3.5 which is marked as red color in Fig. 5. The MG dye removal increased with increase of IR and activation temperature which explains that the interaction between the activation temperature and IR is prominent on MG dye adsorption. These results were in agreement with the study carried by Bello et al. (2012a) which used banana stalk to prepare AC; they found that the activation temperature and IR have significant effects on removal of malachite green dye.

The increase in temperature promotes devolatilization rate resulting in significant effect to the pore structure of AC produced (Sudaryanto et al. 2006). An increase in

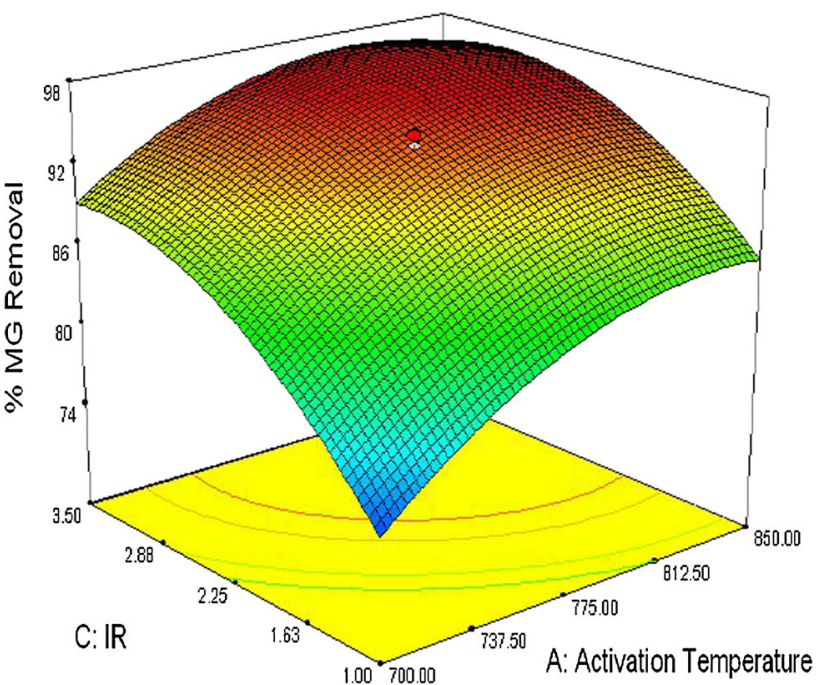

Fig. 5 Response surface plot of MG dye removal of LPAC (effect of activation temperature and impregnation ratio. Activation time $=2 \mathrm{~h}$ )

temperature would increase the volatiles released as a result of intensification in dehydration and elimination reaction which would increase the $\mathrm{C}-\mathrm{KOH}$ (activated carbon impregnated with $\mathrm{KOH}$ ) and $\mathrm{C}-\mathrm{CO}_{2}$ (activated carbon gasified with $\mathrm{CO}_{2}$ ) reaction rate. In fact, at higher temperature, the activation time should just be enough to eliminate all the moisture and volatile components for pores to develop. However, the MG dye removal increased after the temperature exceeded $850{ }^{\circ} \mathrm{C}$ due to the loss of the volatile materials at such temperature. A similar result was obtained in the optimization of preparation conditions for activated carbons from date stones using response surface methodology (Samar and Muthanna 2012). Furthermore, intercalation of potassium metal ion on the carbon sample at high temperatures enhanced the pore development of the LPAC. $\mathrm{KOH}$ is a dehydrating agent that penetrates deep into the structure of the carbon sample causing tiny pores to develop. This resulted in new pore development, thus enhancing the dye adsorption capacity of LPAC. The application of heat to an impregnated sample caused the $\mathrm{CO}_{2}$ and the metal complex to further gasify the carbon, leading to widening of micropore to mesopore ( $\mathrm{Wu}$ and Tseng 2006). However, IR above 3.5 contributed to a drop in MG dye removal due to the reaction between $\mathrm{KOH}$ and carbon leading to presence of excess $\mathrm{K}_{2} \mathrm{CO}_{3}$ and metallic $\mathrm{K}$ blocking the pores of LPAC (El-Hendawy 2005).

Increase in activation temperature and activation time caused more pore to enlarge resulting in enhanced adsorption capacity. However, if it goes beyond the threshold required it causes undesirable characteristics of activated carbon produced (Lua and Yang 2004). The effect can be seen on Fig. 5 where at a very high or low activation 
temperature, the MG dye percent removal was about to decrease. The pore size instead of getting widened; becomes blocked, resulting in a decrease in adsorption capacity of LPAC. Vargas and co-workers stated that increase in temperature and time beyond the maximum range suggested by the software in the experimental design tends to decrease the surface area and mesopore volume. In their work, activation time gave the least significant effect towards MB dye removal (Vargas et al. 2011). In addition, Hameed et al. (2007) also asserted that the removal of dye from rattan sawdust $\mathrm{AC}$ decrease with increasing activation time.

\section{LPAC yield}

Activation temperature $\left(x_{1}\right)$ was the most significant variable to LPAC yield as it showed $F$ value of 48.60 and Prob $>F$ is less than 0.001 , followed by activation time $\left(x_{2}\right)$ and IR $\left(x_{3}\right)$ (Table 5). The interaction effect between activation temperature and activation time were considered to be the most compatible as it shows the highest $F$ value of 8.08 with Prob $>F$ of 0.0139 . Figure 6 shows the threedimensional response surface plot of LPAC yield comprising effect of activation temperature and activation time, while IR was kept at zero level $(I R=2.25)$ whereas Fig. 7 illustrate the effect of activation temperature and IR on the response, with activation time fixed at zero level $(t=2 \mathrm{~h})$. Increase in activation temperature and activation time caused LPAC yield to decrease. As can be seen from Fig. 6, the highest yield was achieved when both variables were at maximum point. Meanwhile, increase in IR decreased the LPAC yield as shown in Fig. 7. The devolatilization, dehydration and elimination reaction of samples at high temperature significantly reduce LPAC yield. As temperature increased, the $\mathrm{C}-\mathrm{KOH}$ and $\mathrm{C}-\mathrm{CO}_{2}$ reaction were increased which leads to decrease in LPAC yield and increase in carbon "burn off" by $\mathrm{KOH}$. This result was in agreement with the work on preparation and characterization of activated carbon from bamboo by microwave-induced phosphoric acid activation (Liu et al. 2010). The KOH impregnation of sample and high activation temperature lead to the breaking of $\mathrm{C}-\mathrm{O}-\mathrm{C}$ and $\mathrm{C}-\mathrm{C}$ bonds, which result in low carbon yield. Samar and Muthanna also found out that as the three variables increased, the date stones yield decreased due to loss of volatile matters and also continuous removal of tar material from the pores, respectively (Samar and Muthanna 2012).

\section{Optimization of operating parameters}

The objective of the experimental design was to find the optimum preparation conditions so that the high AC's yield with high dye removal can be achieved. However, these

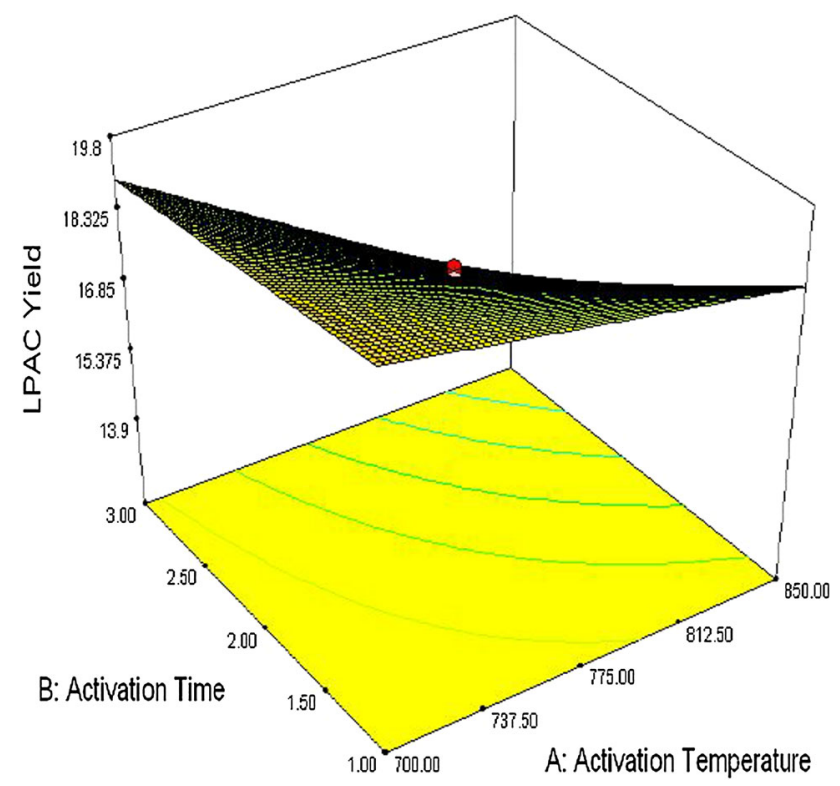

Fig. 6 Response surface plot of LPAC yield (effect of activation temperature and activation time, $I R=2.25$ )

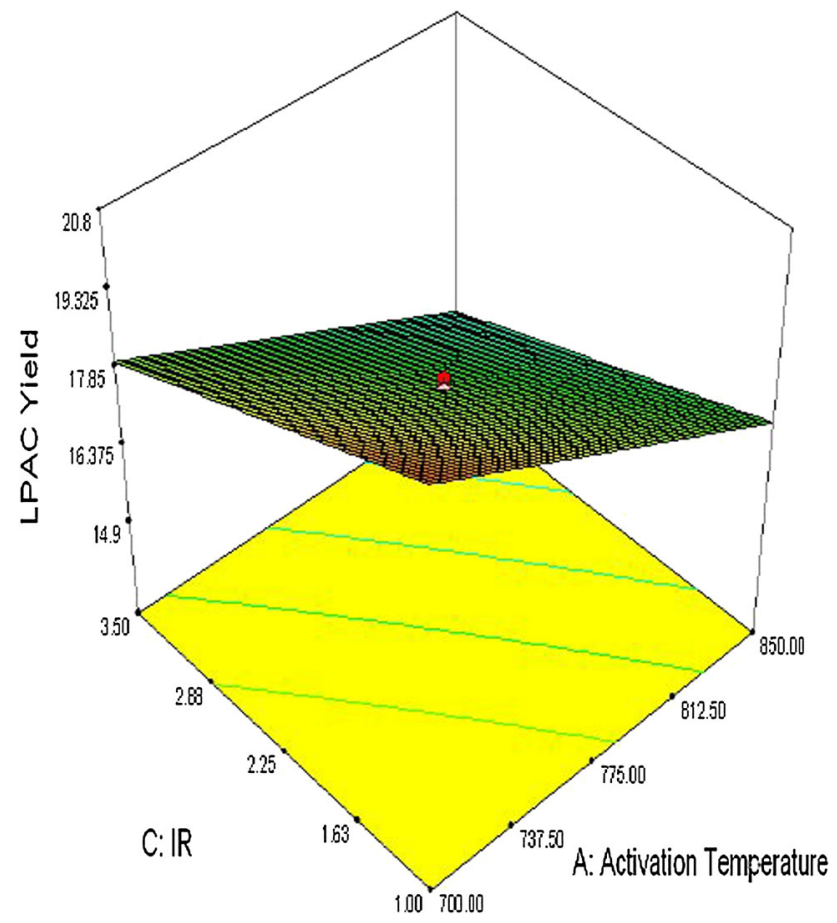

Fig. 7 Response surface plot of LPAC yield (effect of activation temperature and IR, activation time $=2 \mathrm{~h}$ )

responses have different interest region of the factors. As the dye removal increases, the $\mathrm{AC}$ yield decreases and vice versa. Hence, two optimum operating conditions must be determined in each adsorbate. Table 5 showed the model validation for LPAC for dye removal, and AC yield. Optimized parameters were selected based on highest 
Table 6 Model validation for LPAC prepared for MG dye removal

\begin{tabular}{|c|c|c|c|c|c|c|c|c|c|c|}
\hline \multirow{2}{*}{$\begin{array}{l}\text { Activated } \\
\text { carbon }\end{array}$} & \multirow{2}{*}{$\begin{array}{l}\text { Model } \\
\text { desirability }\end{array}$} & \multirow{2}{*}{$\begin{array}{l}\text { Activation } \\
\text { temperature, } x_{1}\left({ }^{\circ} \mathrm{C}\right)\end{array}$} & \multirow{2}{*}{$\begin{array}{l}\text { Activation time, } \\
x_{2}(\mathrm{~h})\end{array}$} & \multirow{2}{*}{$\begin{array}{l}\mathrm{IR} \\
x_{3}\end{array}$} & \multicolumn{3}{|c|}{ MG dye removal (\%) } & \multicolumn{3}{|c|}{ LPAC yield (\%) } \\
\hline & & & & & Predicted & Experimental & $\begin{array}{l}\text { Error } \\
(\%)\end{array}$ & Predicted & Experimental & $\begin{array}{l}\text { Error } \\
(\%)\end{array}$ \\
\hline LPAC & 0.896 & 796 & 1.0 & 2.6 & 95.02 & 94.68 & 0.40 & 18.51 & 17.88 & 3.40 \\
\hline
\end{tabular}

desirability. Optimum condition selected was verified by experimental. Design Expert Software version 7.1.5.1 (STAT-EASE Inc., Minneapolis, USA). It was used to optimize the parameters where the targets were set at maximum values, while the values of variables were set in range under study.

Table 6 shows model validation for MG dye removal by LPAC. The predicted and experimental values for the two responses for each activated AC derived are also presented in the same Table. The optimum conditions of MG dye removal by LPAC was achieved at activation temperature, activation time and IR of $796{ }^{\circ} \mathrm{C}, 1.0 \mathrm{~h}$ and 2.6, respectively. The MG dye percent removal obtained was $94.68 \%$ resulting in $17.88 \%$ LPAC yield. Model desirability approaching unity and with low error value portrays the applicability of the model towards the responses. From the table, relatively small errors less than 0.5 and $64.0 \%$ were obtained for the predicted and the actual values, respectively, indicating that the models are suitable and sufficient to predict the responses. The optimized LPAC samples prepared were further characterized to understand their physical and chemical characteristics.

\section{Conclusion}

The activating agent used for impregnation enhances the surface morphology of LPAC. The quadratic and two factor interaction (2FI) models developed for process optimization and statistical experimental designs were found to be useful for predicting and understanding the interactive effects between process parameters. The optimum conditions of MG dye removal by LPAC are: activation temperature $\left(796{ }^{\circ} \mathrm{C}\right)$, activation time $(1.0 \mathrm{~h})$ and impregnation ratio (2.6), respectively. The percentage of MG dye removal obtained was $94.68 \%$ resulting in $17.88 \%$ LPAC yield. The percentage of error between predicted and experimental results for the removal of $\mathrm{MG}$ dye is $0.4 \%$ showing that the experimental results were in good agreement with that predicted from model.

Acknowledgments The financial support in form of grants from USM, the 3 months USM-TWAS Visiting Researcher Fellowship, FR number: 3240268492 awarded to the corresponding author and the accumulated leave granted to Dr. O.S Bello by his home institution to utilize the fellowship is thankfully recognized.
Open Access This article is distributed under the terms of the Creative Commons Attribution 4.0 International License (http:// creativecommons.org/licenses/by/4.0/), which permits unrestricted use, distribution, and reproduction in any medium, provided you give appropriate credit to the original author(s) and the source, provide a link to the Creative Commons license, and indicate if changes were made.

\section{References}

Abdullah MHRO, Ch'ng PE, Yunus NA (2012) Some Physical Properties of Musk Lime (Citrus Microcarpa). World Acad Sci Eng Technol 6:12-25

Ahmad AA, Hameed BH (2010) Effect of preparation conditions of activated carbon from bamboo waste for real textile wastewater. J Hazard Mater 173:487-493

Auta M, Hameed BH (2011) Optimized waste tea activated carbon for adsorption of Methylene Blue and Acid Blue 29 dyes using response surface methodology. Chem Eng J 175:233-243

Bello OS (2013) Adsorptive removal of malachite green with activated carbon prepared from oil palm fruit fibre by $\mathrm{KOH}$ Activation and $\mathrm{CO}_{2}$ Gasification. S Afr J Chem 66:32-41

Bello OS, Ahmad MA (2011a) Adsorptive removal of a synthetic textile dye using coca pod husks. Toxicol Environ Chem 93:1298-1308

Bello OS, Ahmad MA (2011b) Adsorption of dyes from aqueous solution using chemical activated mango peels. 2nd Inter Conf Environ Sci Technol (ICEST) 2:108-113

Bello OS, Ahmad MA (2011c) Response surface modelling and optimization of remazol brilliant blue reactive dye removal using periwinkle shell based activated carbon. Sep Sci Technol 46:2367-2379

Bello OS, Ahmad MA (2011d) Removal of remazol brilliant violet5R dye using periwinkle shell. Chem Ecol 27:481-492

Bello OS, Ahmad MA (2012a) Preparation and characterization of activated carbon derived from rubber seed coat. Chemistry. Bulg J Sci Edu 21:389-395

Bello OS, Ahmad MA (2012b) Coconut (Cocos nucifera) shell based activated carbon for the removal of malachite green dye from aqueous solutions. Sep Sci Technol 47:903-912

Bello OS, Semire B (2012) Equilibrium, kinetic and quantum chemical studies on the adsorption of Congo red using Imperata cylindrica leaf powder activated carbon. Toxicol Environ Chem 94:1114-1124

Bello OS, Adeogun IA, Ajaelu JC (2008) Adsorption of methylene blue onto activated carbon derived from periwinkle shells: kinetics and equilibrium studies. Chem Ecol 24:285-295

Bello OS, Ahmad MA, Ahmad N (2012a) Adsorptive features of banana (Musa paradisiaca) stalk-based activated carbon for malachite green dye removal. Chem Ecol 28:153-167

Bello OS, Fatona TA, Falaye FS, Osuolale OM, Njoku VO (2012b) Adsorption of eosin dye from aqueous solution using groundnut hull-based activated carbon: kinetic, equilibrium, and thermodynamic studies. Environ Eng Sci 29:186-194 
Bello OS, Tan TS, Ahmad MA (2012c) Adsorption of remazol brilliant violet-5R reactive dye from aqueous solution by cocoa pod husk-based activated carbon: kinetic, equilibrium and thermodynamic studies. Asia Pac J Chem Eng 7:378-388

Bello OS, Oluwole OA, Njoku VO (2013) Fly Ash: an alternative to powdered activated carbon for the removal of eosin dye from aqueous solutions. Bull Chem Soc Ethiopia 27:191-204

Din ATM, Hameed BH, Ahmad AL (2009) Batch adsorption of phenol onto physiochemical-activated coconut shell. J Hazard Mater 161:1522-1529

Dogan M, Alkan M, Onganer Y (2000) Adsorption of methylene blue from aqueous solution onto perlite. Wat Air Soil Poll 120:229-248

El-Hendawy ANA (2005) Surface and adsorptive properties of carbons prepared from biomass. Appl Surf Sci 252:287-295

Foo KY, Hameed BH (2009a) Value-added utilization of oil palm ash: a superior recycling of the industrial agricultural waste. J Hazard Mater 172:523-531

Foo KY, Hameed BH (2009b) Utilization of rice husk ash as novel adsorbent: a judicious recycling of the colloidal agricultural waste. Adv Coll Interf Sci 152:39-47

Hameed BH, Ahmad AL, Latiff KNA (2007) Adsorption of basic dye (Methylene Blue) onto activated carbon prepared from rattan sawdust. Dyes Pigm 75:143-149

Hasan MB (2008) Adsorption of reactive azo dyes on chitosan/oil palm ash composite adsorbent: batch and continuous studies. M Sc. Thesis. Universiti Sains Malaysia

IUPAC (1972) IUPAC manual of symbols and terminology. Pure Appl Chem 31:579-638

Kilic M, Apaydin-Varol E, Pütün AE (2011) Adsorptive removal of phenol from aqueous solutions on activated carbon prepared from tobacco residues: equilibrium, kinetics and thermodynamics. J Hazard Mater 189:397-403

Li W, Zhang LB, Peng JH, Li N, Zhu XY (2008) Preparation of high surface area activated carbons from tobacco stems with $\mathrm{K}_{2} \mathrm{CO}_{3}$ activation using microwave radiation. Ind Crops Prod 27:341-347

Liu QS, Zheng T, Wang P, Guo L (2010) Preparation and characterization of activated carbon from bamboo by microwave-induced phosphoric acid activation. Ind Crops Prod 31:233-238

Lua AC, Yang T (2004) Effect of activation temperature on the textural and chemical properties of potassium hydroxide activated carbon prepared from pistachio-nut shell. J Coll Interf Sci 274:594-601

Robinson T, Chandaran B, Nigam P (2002) Removal of dyes from a synthetic dye effluent by biosorption on wheat straw. Wat Res $36: 2830-2842$

Sahu JN, Acharya J, Meikap BC (2010) Optimization of production conditions for activated carbons from Tamarind wood by zinc chloride using response surface methodology. Bioresour Technol 101:1974-1982
Samar K, Muthanna J (2012) Optimization of preparation conditions for activated carbons from date stones using response surface methodology. Powder Technol 224:101-108

Sathishkumar P, Arulkumar M, Palvannan T (2006) Utilization of agro-industrial waste Jatropha curcas pods as an activated carbon for the adsorption of reactive dye Remazol Brilliant Blue $\mathrm{R}$ (RBBR). J Cleaner Prod 87:899-905

Sudaryanto SB, Hartono W, Irawaty H, Hindarso S Ismadji (2006) High surface area activated carbon prepared from cassava peel by chemical activation. Bioresour Technol 97:734-739

Sun Q, Yung L (2003) The adsorption of basic dyes from aqueous solution on modified peat- resin particle. Wat Res 37:1535-1544

Sundarrajan M, Frenandis AZ, Subrahmanyam G, Prabhudesai S, Krishnamurthy SC, Rao KV (2000) Over expression of G1/S cyclins and PCNA and their relationship to tyrosine phosphorylation and dephosphorylation during tumor promotion by metanil yellow and malachite green. Toxicol Lett 116:119-130

Vargas AMM, Cazetta AL, Kunita MH, Silva TL, Almeida VC (2011) Adsorption of Methylene blue on activated carbon produced from flamboyant pods (Delonix regia): study of adsorption isotherms and kinetic models. Chem Eng J 168:722-730

Verma VK, Mishra AK (2006) Removal of dyes by the wheat straw carbon. Ecol Environ Conserv 12:755-757

Wasewar KL, Prasad B, Gullipalli S (2009) Adsorption of selenium using bagasse fly ash. Clean 37:534-543

Wu FC, Tseng RL (2006) Preparation of highly porous carbon from fir wood by $\mathrm{KOH}$ etching and $\mathrm{CO}_{2}$ gasification for adsorption of dyes and phenols from water. J Colloid Interf Sci 294:21-30

Yahaya NEM, Pakir MF, Latiff M, Abustan I, Bello OS, Ahmad MA (2010a) Process optimisation for $\mathrm{Zn}$ (II) removal by activated carbon prepared from rice husk using chemical activation. Int $\mathbf{J}$ Eng Technol 10:132-136

Yahaya NEM, Pakir MF, Latiff M, Abustan I, Bello OS, Ahmad MA (2010b) Effect of preparation conditions of activated carbon prepared from rice husk by $\mathrm{CO}_{2}$ activation for removal of $\mathrm{Cu}(\mathrm{II})$ from aqueous solution. Int J Eng Technol 10:47-51

Yahaya NEM, Pakir MF, Latiff M, Abustan I, Bello OS, Ahmad MA (2011a) Adsorptive removal of $\mathrm{Cu}(\mathrm{II})$ using activated carbon prepared from rice husk by $\mathrm{ZnCl}_{2}$ activation and subsequent gasification with $\mathrm{CO}_{2}$. Int J Eng Technol 11:207-211

Yahaya NEM, Pakir MF, Latiff M, Abustan I, Bello OS, Ahmad MA (2011b) Fixed bed column study for $\mathrm{Cu}$ (II) removal from aqueous solutions using rice husk based activated carbon. Int $\mathbf{J}$ Eng Technol 11:248-252

Zainudin NF, Lee KT, Kamaruddin AH, Bhatia S, Mohamed AR (2005) Study of adsorbent prepared from oil palm ash (OPA) for flue gas desulfurization. Sep Purif Technol 45:50-60

Zawani Z, Luqman CA, Choong TSY (2009) Equilibrium, kinetics and thermodynamic studies: adsorption of Remazol black 5 on the palm kernel shell activated carbon (PKS-AC). Euro J Sci Res 37:63-71 